\title{
Syndactyly type 8
}

INSERM

\section{Source}

INSERM. (1999). Orphanet: an online rare disease and orphan drug data base. Syndactyly type 8. ORPHA:2498

Syndactyly type 8 is a rare, genetic, non-syndromic, congenital limb malformation characterized by unilateral or bilateral fusion of the fourth and fifth metacarpals with no other associated abnomalities. Patients present shortened fourth and fifth metacarpals with excessive separation between their distal ends, resulting in marked ulnar deviation of the little finger and an inability to bring the fifth finger in parallel with the other fingers. 